\title{
Simultaneous curvature correction at the time of the penile fracture repair: surgical and functional outcomes
}

\author{
Lucio Dell'Atti ${ }^{1}$ \\ Simone Scarcella ${ }^{2}$ \\ Matteo Tallè ${ }^{2}$ \\ Massimo Polito ${ }^{3}$ \\ Andrea Benedetto Galosi ${ }^{2}$ \\ 'Department of Urology, University \\ Hospital "Ospedali Riuniti”, Ancona, Italy; \\ ${ }^{2}$ Department of Urology, Polytechnic \\ University of Marche, Ancona, Italy; \\ ${ }^{3}$ Andrology Unit, University Hospital \\ "Ospedali Riuniti", Ancona, Italy
}

This article was published in the following Dove Press journal: Research and Reports in Urology

Purpose: After a penile fracture (PF), an early surgical exploration and defect closure of the lesions are recommended to prevent long-term complications. However, postoperative unsatisfactory penile curvatures are frequent in the literature. In this study, we wished to present surgical outcomes of PF after surgical repair approach with an early intraoperative curvature correction and update our series with postoperative follow-up.

Patients and methods: An institutional retrospective review study of 36 patients undergoing surgical treatment for PF was performed. Mean age of patients was 53.2 years. All surgical explorations were performed within 12 hours after the traumatic event. The surgical repair with a contemporary penile plication was then made to straighten the tunica angulations in patients with curvature greater than $30^{\circ}$, using $2-3$ pairs of $2-0$ absorbable suture of polydioxanone.

Results: The length of the tear ranged from 8 to $20 \mathrm{~mm} .77 .7 \%$ of the patients required a correction of the cavernous body deviation. No early complications occurred in any case. The median patient stays in the hospital was 3.4 days. At a mean follow-up of 20.6 months, all patients were able to insert the penis in the partner's vagina, and were satisfied overall with sexual intercourse; three patients $(10.7 \%)$ reported residual pain and discomfort for the knots of the sutures.

Conclusions: An early intraoperative curvature correction may be used for a variety of angulation deformities and severe degrees of deviations secondary to a repair after penile trauma, and may be helpful in preventing postoperative morbidity.

Keywords: penile fracture, penile curvature, corpora cavernosa, corporoplasty

\section{Introduction}

Penile fracture $(\mathrm{PF})$ is defined as a rupture of the tunica albuginea occurring during penile erection. ${ }^{1}$ The most common cause of PF is sexual intercourse. Other reported causes include masturbation, rolling over the erect penis, and direct trauma. ${ }^{2}$ The incidence of PF is difficult to evaluate because an unknown number of men do not require medical attention for fear or embarrassment. ${ }^{3}$ It is linked to penile curvature greater than $60^{\circ}$ in more than $20 \%$ of the patients. ${ }^{3}$ In most cases, diagnosis of PF can be made clinically. The patients usually report hearing a cracking sound, followed by rapid detumescence of erect penis, intense local pain, hematoma, bruising, and deformity of the penis. ${ }^{1-3}$ Hematuria is present in $9-38 \%$ of the patients. ${ }^{4}$ Early surgical exploration and defect closure of the lesions are recommended to prevent long-term complications. ${ }^{5,6}$ However, postoperative
Correspondence: Lucio Dell'Atti Department of Urology, Polytechnic University of Marche Region, University Hospital "Ospedali Riuniti", 7I Conca Street, Ancona 60126, Italy

Tel +39 07I 5966523

Fax +39 07I 5963367

Email dellatti@hotmail.com 
unsatisfactory penile curvatures are frequent in the literature. ${ }^{7,8}$ In this study, we wished to present surgical outcomes of PF after surgical repair approach with an early intraoperative curvature correction, if needed, and update our series with postoperative follow-up.

\section{Patients and methods}

We performed an institutional retrospective review study of patients undergoing surgical treatment for PF by a single surgeon (LD) at our tertiary academic referral center between 2007 and 2017. All patients had a singular tear of the corpora cavernosa. The length of the tear was determined at the time of the repair. Only patients with a singular tear of the corpora cavernosa and a minimum follow-up of 6 months were included in the study. All surgical explorations were performed within 12 hours after the traumatic event. Detailed information on possible postoperative pain, discomfort, irregularities of penile shaft and penile shortening were provided to the patients preoperatively. Surgery was performed with the patients under epidural anesthesia. During surgery, foley catheter $(14 \mathrm{Fr}-16 \mathrm{Fr})$ was inserted for every patient to prevent an inadvertent injury to the urethra and removed on the first postoperative day. The surgical procedure started a coronal incision to $1 \mathrm{~cm}$ from the gland line. A careful degloving with preparatory isolation of the dissection plan between dartos and Buck's fascia was made. After exposing the corpora cavernosa and evacuating the hematoma, the location and length of the tear in the tunica was recorded. In all cases of our series, the tear in the tunica was noted to be transverse. The size of the tear ranged between 8 and $20 \mathrm{~mm}$ in length. The tunica defect was closed by a running suture of absorbable 2-0 polydioxanone (PDS, Ethicon, Somerville, NJ, USA) with inverted knots. A tourniquet was set at the base of the penis. Artificial erection was induced by injection of sterile saline solution into the corpora cavernosa through a 19 gauge butterfly needle to determine the integrity of the suture and the degree of deviation. The body deviation was defined as a curvature $>30^{\circ}$, measured with a goniometer. In patients that had required to correct a cavernous body deviation, the effect of the opposite correction was simulated using Allis clamps. Penile plication was then performed to straighten the tunica angulations in all patients with curvature greater than $30^{\circ}$, using 2-3 pairs of a $2-0$ absorbable suture of polydioxanone through the full thickness of the tunica albuginea. Once all plication sutures were placed, the erect penis was examined for evaluation of its straightness (Figure 1). At the end, a circular dressing with light pressure was applied for 24 hours, and the foley catheter was removed the following day. Antibiotic prophylaxis was dispensed routinely during surgery (cefazolin $2 \mathrm{~g}$ in single doses) and at discharge (amoxicillin-clavulanate $875-125 \mathrm{mg}$ every 8 hours) for 10 days. We did not suppress nocturnal erection, but patients were advised to abstain from sexual intercourse for two months.

\section{Postoperative evaluation and follow-up}

Follow-up was planned, involving a clinical evaluation during the first month, an evaluation of voiding and sexual function after the third and sixth month after surgery. All patients were subsequently reviewed with the postoperative
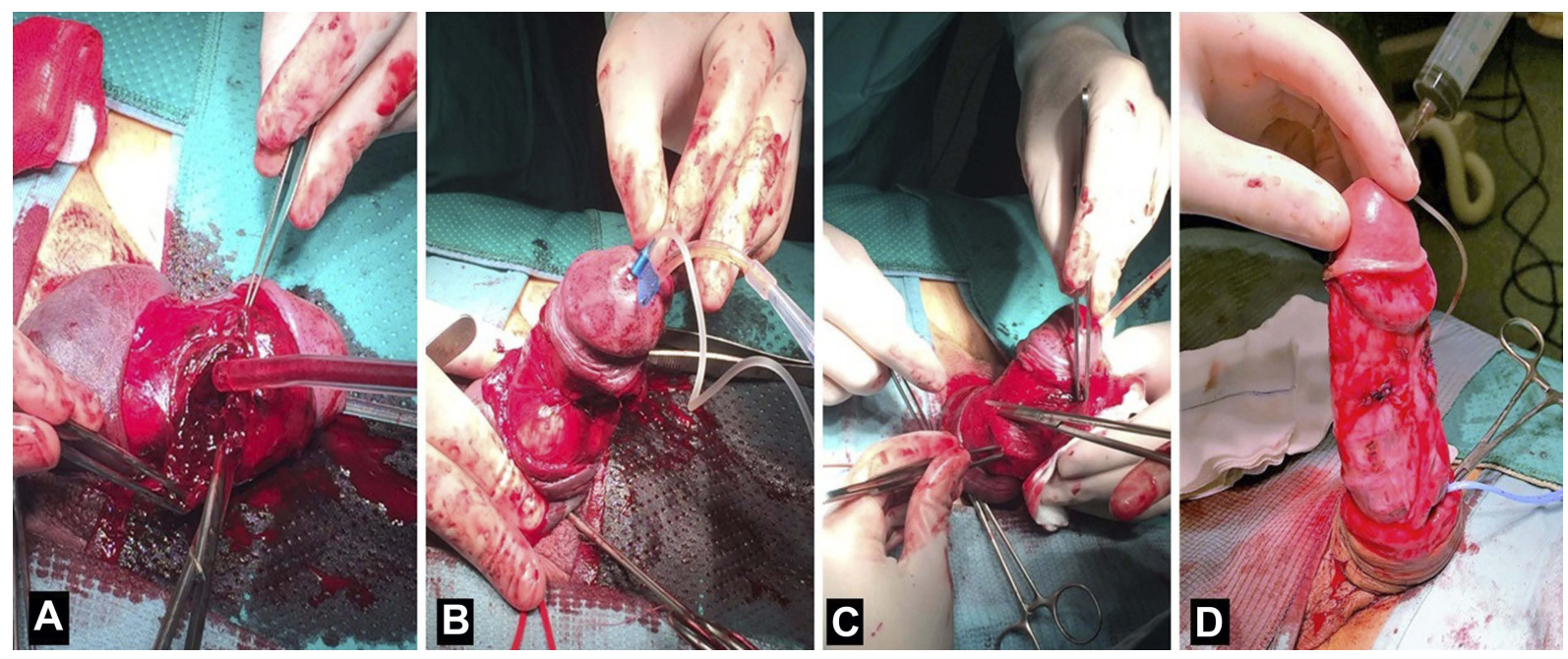

Figure I Illustration of the surgical technique. (A): After evacuating the hematoma, the location and length of the tear in the tunica is exposed and, the defect is closed by a running suture of absorbable 2-0 polydioxanone with inverted knots. (B): Artificial erection is induced by injection of sterile saline solution into the corpora cavernosa to check the integrity of the suture and the degree of deviation. (C): In patients that required the correction of the cavernous body deviation, a penile plication is performed to straighten the tunica angulations using 2-3 pairs of a 2-0 absorbable suture. (D): Once all plication sutures are placed, the erect penis is examined for evaluation of its straightness. 
survey of Chahal et $\mathrm{al}^{8}$, a disease-specific patient questionnaire to determine various aspects of the results of surgery related to sexual function, cosmesis, and patient satisfaction as: changes in erectile function, body deviation, development of palpable nodules and quality of sexual experiences.

\section{Statistical analysis}

The data were analyzed in a common database. Qualitative variables were described using absolute frequencies and percentages. Quantitative variables were described using the mean, standard deviation, median, and quartiles. All statistical analyses were conducted using SPSS version 23 (IBM Corp. Armonk, NY, USA).

\section{Results}

\section{Patient demographics}

A total of 36 patients having PF of the corpora cavernosa were included in this review. Patient characteristics are summarized in Table 1. Median age of patients was 53.2 years (range 26-74). Patients in the sixth decade (13/36: 36.1\%) were predominantly affected. Twenty-two $(61.1 \%)$ were married and $14(38.9 \%)$ were single at the time of presentation. The seasonal variation of the diagnosed cases was as follows: 11 cases $(30.5 \%)$ in the spring, $16(44.5 \%)$ in the summer, 4 $(11.1 \%)$ in the autumn, $5(13.9 \%)$ in the winter. The injury was caused during vaginal intercourse in all patients: 14 (38.9\%) patients in the missionary position and 21 (61.1\%) patients in "the woman on top" position.

\section{Diagnosis of PF}

PF was fundamentally diagnosed on data obtained from the medical history, clinical and ultrasonographic assessment. All patients presented with the typical clinical picture of a characteristic sound at the time of injury, detumescence, pain, and hematoma. Ultrasound showed an irregular hypoechoic or hyperechoic defect at the cavernosal rupture site. The exact location of the tear has been demonstrated as an interruption of the thin echogenic line of the tunica albuginea, and often showed an association of hematoma. In 31 (86.1\%) patients a good ultrasound correlation with the results of surgery was confirmed. Retrograde urethrography was performed in two cases. The interval between injury and presentation ranged between 4 and 12 hours.

\section{Intraoperative findings}

PF was confirmed by the surgery in all patients. All tears in the tunica albuginea were unilateral and transverse with concomitant partial urethral involvement in four cases (4/36; $8.3 \%)$. The length of the tear ranged from 8 to $20 \mathrm{~mm}$. The defect was in the mid-shaft in 14 patients $(38.9 \%)$ or proximal shaft in 22 patients (61.1\%): 25 cases (69.4\%) right side and 11 cases $(30.6 \%)$ left side. After the tunica defect was closed by a running suture, 28 patients $(77.7 \%)$, with an intraoperative curvature greater than $30^{\circ}$, required to correct the cavernous body deviation. A transurethral foley catheter was placed in all patients for 24 hours, except for four patients with a urethral injury the foley catheter fixed for one week. No early complications occurred in any case. After removing the bladder catheter, median patient stay in the hospital was 3.4 days (range 2-8).

\section{Follow-up of patients after surgical treatment}

The mean follow-up was 20.6 months (range 6-42). At 6 months follow-up, $1 / 4$ (25\%) of patients with urethral lesions had voiding dysfunction and developed a urethral stricture. Results regarding outcomes and disablement of sexual life of patients are shown in Table 2. At follow-up $3 / 28(10.7 \%)$ patients presented (moderate/severe) erectile dysfunction needing treatment with phosphodiesterase type 5 inhibitors. At follow-up, all treated patients were able to insert the penis in the partner's vagina, all patients were satisfied overall with sexual intercourse, three patients reported residual pain and discomfort for the knots of the sutures.

\section{Discussion}

$\mathrm{PF}$ is an emergency in urology. ${ }^{1}$ The diagnosis of $\mathrm{PF}$ is often a clinical diagnosis through history and physical examination. However, after a typical history and physical exam, patients can need radiographic studies. ${ }^{3}$ Even though many authors have evaluated the diagnostic role of various radiographic modalities, such as ultrasonography, cavernosography, and magnetic resonance imaging, a surgical exploration is mostly necessary. ${ }^{9-11}$ The only significant imaging study is a retrograde urethrogram, which should be selectively made to identify a concomitant urethral injury that occurs when patients present blood at the urethral meatus or haematuria. ${ }^{12}$ We found that an ultrasonographic study (US) to be a very helpful tool in the diagnosis of PF. We use penile ultrasonography routinely. US was able to show a tunical tear in $86.1 \%$ of our cases, such as Shukla et $\mathrm{al}^{13}$, that reported a grading system based on ultrasonography and a sensitivity of $95 \%$ in 15 patients. The location of the $\mathrm{PF}$ is usually transverse and 
Table I Distribution of clinical characteristics and intraoperative findings in patients affected by penile fracture

\begin{tabular}{|c|c|}
\hline Patients characteristics & $(n=36)$ \\
\hline Age (years), median (range) & $53.2(26-74)$ \\
\hline $21-30$, n (\%) & $2(5.6)$ \\
\hline $31-40, n(\%)$ & $6(16.7)$ \\
\hline $4 I-50, n(\%)$ & $7(19.4)$ \\
\hline $5 \mathrm{I}-60, \mathrm{n}(\%)$ & $13(36.1)$ \\
\hline $61-70, n(\%)$ & $5(13.9)$ \\
\hline $7 \mid-80, n(\%)$ & $3(8.3)$ \\
\hline \multicolumn{2}{|l|}{ Marital status, n (\%) } \\
\hline Married & $22(6 \mathrm{I} . \mathrm{I})$ \\
\hline Unmarried & $14(38.9)$ \\
\hline \multicolumn{2}{|l|}{ Season variation, $\mathrm{n}$ (\%) } \\
\hline Autumn & $4(11.1)$ \\
\hline Winter & $5(13.9)$ \\
\hline Spring & II (30.5) \\
\hline Summer & $16(44.5)$ \\
\hline \multicolumn{2}{|l|}{ Clinical signs and symptoms, $n(\%)$} \\
\hline Penile hematoma and swelling & $36(100)$ \\
\hline Penile pain & $28(77.7)$ \\
\hline Acoustic cracking & $16(44.4)$ \\
\hline Detumescence & $13(36.1)$ \\
\hline Hematuria & $5(13.9)$ \\
\hline \multicolumn{2}{|l|}{ Sexual mechanism of injury, $n(\%)$} \\
\hline Missionary position & $14(38.9)$ \\
\hline Woman on top position & $22(61.1)$ \\
\hline \multicolumn{2}{|l|}{ Laterality of the lesion, $\mathrm{n}(\%)$} \\
\hline Right-side of corpus cavernosum & $25(69.4)$ \\
\hline Left-side of corpus cavernosum & II (30.6) \\
\hline \multicolumn{2}{|l|}{ Site of the lesion, $\mathrm{n}(\%)$} \\
\hline Ventral & $10(27.8)$ \\
\hline Dorsal & $5(13.9)$ \\
\hline Lateral & $21(58.3)$ \\
\hline Concomitant urethral rupture & $4(8.3)$ \\
\hline Length of the tear $(\mathrm{mm})$, median (range) & $14.3(8-20)$ \\
\hline Patients undergoing curvature correction & $28(77.7)$ \\
\hline
\end{tabular}

unilateral, as confirmed in our study. ${ }^{8}$ The incidence of concomitant urethral rupture is much lower than $22 \%$ of the patients. ${ }^{4}$ In our cases, there were only four patients $(11.1 \%)$ with an incomplete urethral disruption where urethral anastomosis of the tear was needed. Many studies reported that an immediate surgical repair provides better long-term outcomes than conservative treatments. ${ }^{12,14}$ Muentener et $\mathrm{al}^{15}$, observed that the success rate was $92 \%$ for immediate surgical treatment and 59\% for conservative management. Yapanoglu et $\mathrm{al}^{16}$, and Gamal et $\mathrm{al}^{17}$, also
Table 2 Outcomes of patients affected by penile fracture after surgical treatment with curvature correction ( $\mathrm{n}: 28$ patients)

\begin{tabular}{|l|l|}
\hline Follow-up (months), median (range) & $\mathbf{2 0 . 6}$ (6-42) \\
\hline Subjective loss of penile length, $\mathrm{n}(\%)$ & $8(28.6)$ \\
Pain at erection, $\mathrm{n}(\%)$ & $\mathrm{I}(2.7)$ \\
Pain during sexual intercourse, $\mathrm{n}(\%)$ & $2(7.1)$ \\
Erectile dysfunction, $\mathrm{n}(\%)$ & $3(10.7)$ \\
Recurrent curvature, $\mathrm{n}(\%)$ & $0(0)$ \\
Change in penile sensation, $\mathrm{n}(\%)$ & $4(14.3)$ \\
Palpable suture knots, $\mathrm{n}(\%)$ & $3(10.7)$ \\
Voiding dysfunction, $\mathrm{n}(\%)$ & $2(7.1)$ \\
Urethral stricture development, n (\%) & $\mathrm{I}(2.7)$ \\
\hline
\end{tabular}

reported similar results, and found that a prompt surgical treatment improved outcome, rather than conservative treatment. The conservative management of $\mathrm{PF}$ has been linked to penile curvature greater than $60^{\circ}$ in more than $20 \%$ of the patients, debilitating plaques in $25-30 \%$ of the patients, and significantly longer hospitalization times. ${ }^{14,15,17}$ However, postoperative unsatisfactory penile curvatures are frequent in the literature. In a recent systematic review Wong and collegues ${ }^{18}$ comparing immediate vs delayed surgical repair of the PF noted that in the immediate repair group, the percent of patients with postoperative ED, tunical scars, and curvature were $6.6 \%, 5.4 \%$, and $1.8 \%$, respectively, while in the delayed group, the rates of ED, tunical scars, and curvature were $4.5 \%$ across the board. Amer et al ${ }^{19}$, in a recent meta-analysis reported that the incidence of penile curvature after PF repair is around $2.7 \%$ and it is questionable whether routine immediate plication would be beneficial. In our cases series, after the tunica scars were closed, $77.7 \%$ of the patients presented an intraoperative curvature greater than $30^{\circ}$, and required a correction of the cavernous body deviation. Our results in terms of curvature rates detected after the repair are far from those reported in the literature. First, we had a greater median length of tunical scar $(14.3 \mathrm{~mm})$, compared to that reported to other authors. Second, we have corrected deviations from degrees greater than $30^{\circ}$ compared to those corrected by other authors in the literature (greater than $60^{\circ}$ ). Reconstruction of the corporal bodies depends on the extent of the tunical tear. The optimal surgical treatment for PF is still debatable, and results concerning the quality of life in regard to the longterm outcomes of genital reconstruction surgery are still practically available. ${ }^{3,5,16,17}$ Several incisions to accede the injury site have been reported by various authors including a circumcising degloving incision, inguinoscrotal, lateral, and midline incision. ${ }^{19,20} \mathrm{~A}$ degloving after the subcoronal 
incision was utilized in our patients because we believe that it consents an excellent exposure of the whole penis and urethra. For repair of tear of the tunica albuginea, we chose to use absorbable suture (PDS, Ethicon, Somerville, NJ, USA) that minimizes the variability of tensile strength retention and residual postoperative fibrosis. Therefore, this suture does not leave a residual material with the consequent risks of infection and major aesthetic alterations on the surface of the skin. The non-absorbable suture with the knots buried in the tunica albuginea has been recommended for recurrent cases, although residual postoperative fibrosis and a painful syndrome may be associated with its use. ${ }^{21}$ We always performed an artificial erection with the injection of sterile saline solution into the corpora cavernosa to check the seal of suture and the presence of penile deviations that can require a contralateral correction. At our institution, we find plication to be a versatile approach that can be used in a variety of clinical situations with curvature approaching $90^{\circ}$ and significative deformities. ${ }^{22}$ Independent of penile deviation, a PF repair determines penile shortening as a result of the non-expansible and fibrotic scarring of the tunica albuginea. ${ }^{23}$ Perovic et $\mathrm{al}^{24}$, showed that an incision or excision of the contralateral tunica with grafting of the defect should correct this deviation, but the grafting techniques have not invariably resulted in a reclamation of lost penile length caused by the repair process itself. We traditionally utilize absorbable sutures for penile plication because there is a risk of palpable suture knots. However, the knots of the nonabsorbable sutures are often palpable with discomfort in some patients. Recently, Basiri et $\mathrm{al}^{25}$, reported in a randomized trial with 38 patients comparing nonabsorbable and absorbable sutures in plication surgery of the corpora cavernosa. Both sutures resulted in a satisfactory correction of the curvature in $88 \%$ of the patients. However, a significantly higher number of patients were able to touch the sutures in the non-absorbable group (39\%) vs absorbable group (6\%). In our cohort of study, we observed $10.7 \%(3 / 28)$ of patients that were able to feel the knots of absorbable sutures, and one of these patients had pain or discomfort to touch the knots.

The limitations of the present study are evident. The retrospective nature of our study may result in unrecognized biases. First, all surgeries were performed at a single high-volume institution by a single experienced surgeon, which could have influenced outcomes. Our data must be validated with future multicenter studies. Second, the lack of a control group without an early intraoperative curvature correction to assess the impact on surgical and functional outcomes surgical time, and complications. Third, curvature recurrence, nodularity, postoperative erections, and loss of penile length were patient-reported and not validated objectively with a pharmacologically induced erection.

\section{Conclusion}

To the best of our knowledge, this paper is the first to describe the intraoperative surgical technique for contralateral correction of penile deviations after repairing a PF in a large cohort of patients. Our results support that an immediate and contemporary plication technique as early intraoperative curvature correction after a PF, if needed, provides certain advantages. This approach may be used for a variety of angulation deformities and severe degrees of deviations secondary to a repair after penile trauma, and may be helpful in preventing postoperative morbidity. Further prospective and comparative studies are needed into the different surgical options after a PF. We mean to use the present results in counsel future patients before penis surgical repair.

\section{Ethical approval}

Ethical approval was given by University Hospital "Ospedali Riuniti" - Ancona (Italy) ethics committee for reporting this case series.

\section{Ethics statement}

All procedures performed in studies involving human participants were in accordance with the ethical standards of the institutional and/or national research committee and with the 1964 Helsinki declaration and its later amendments or comparable ethical standards.

\section{Consent}

We have obtained a written informed consent from these patients for all of the anonymized information to be published.

\section{Author contributions}

All authors contributed to data analysis, drafting and revising the article, gave final approval of the version to be published, and agree to be accountable for all aspects of the work.

\section{Disclosure}

The authors report no conflicts of interest in this work. The abstract of this paper was presented at the Annual Meeting of the American Urological Association's 2018 as a poster presentation/conference talk with interim findings. The 
poster's abstract was published in "Poster Abstracts" in Journal of Urology 2018; Vol 199 (4S); e66: www.auajour nals.org/doi/pdf/10.1016/j.juro.2018.02.228

\section{References}

1. Mahapatra RS, Kundu AK, Pal DK. Penile fracture: our experience in a tertiary care hospital. World J Mens Health. 2015;33:95-102. doi:10.5534/wjmh.2015.33.2.95

2. Jack GS, Garraway I, Reznichek R, Raijfer J. Current treatment options for penile fractures. Rev Urol. 2004;6:114-120.

3. Eke N. Fracture of the penis. Br J Surg. 2002;89:555-565. doi:10.1046/j.1365-2168.2002.02075.x

4. Fergany AF, Angermeier KW, Montague DK. Review of cleveland clinic experience with penile fracture. Urology. 1999;54:352-355.

5. Mazaris EM, Livadas K, Chalikopoulos D, Bisas A, Deliveliotis C. Penile fractures: immediate surgical approach with a midline ventral incision. BJU Int. 2009;104:520-523. doi:10.1111/j.1464-410X.2009.08455.x

6. Kamdar C, Mooppan UM, Kim H, Gulmi FA. Penile fracture: preoperative evaluation and surgical technique for optimal patient outcome. BJU Int. 2008;102:1640-1644. doi:10.1111/j.1464-410X.2008.07902.x

7. El-Taher AM, Aboul-Ella HA, Sayed MA, Gaafar AA. Management of penile fracture. $J$ Trauma. 2004;56:1138-1140.

8. Chahal R, Gogoi NK, Sundaram SK, Weston PM. Corporal plication for penile curvature caused by Peyronie's disease: the patients' perspective. BJU Int. 2001;87:352-356.

9. Nizamani WM, Ali SI, Vaswani AK, Shahani BK. Ultrasound diagnosis of penile fracture. J Coll Physicians Surg Pak. 2015;25:S12-3. doi:10.2015/JCPSP.S84S85

10. Nomura JT, Sierzenski PR. Ultrasound diagnosis of penile fracture. J Emerg Med. 2010;38:362-365. doi:10.1016/j.jemermed.2008.03.010

11. Abolyosr A, Moneim AE, Abdelatif AM, Abdalla MA, Imam HM. The management of penile fracture based on clinical and magnetic resonance imaging findings. BJU Int. 2005;96:373-377.

12. Hatzichristodoulou G, Dorstewitz A, Gschwend JE, Herkommer K, Zanti N. Surgical management of penile fracture and long-term outcome on erectile function and voiding. $J$ Sex Med. 2013;10:1424-1430. doi:10.1111/jsm.12107
13. Shukla AK, Bhagavan BC, Sanjay SC, Krishnappa N, Sahadev R. Role of ultrasonography in grading of penile fractures. $J$ Clin Diagn Res. 2015;9:TC01-3. doi:10.7860/JCDR/2015/11628.5754

14. Bolat MS, Özen M, Önem K, Açıkgöz A, Asci R. Effects of penile fracture and its surgical treatment on psychosocial and sexual function. Int J Impot Res. 2017;29:244-249. doi:10.1038/ijir.2017.31

15. Muentener M, Suter S, Hauri D, Sulser T. Long-term experience with surgical and conservative treatment of penile fracture. J Urol. 2004;172:576-579. doi:10.1097/01.ju.0000131594.99785.1c

16. Yapanoglu T, Aksoy Y, Adanur S, Kabadayi B, Ozturk G. Seventeen years' experience of penile fracture: conservative vs. surgical treatment. $J$ Sex Med. 2009;6:2058-2063. doi:10.1111/j.17436109.2009.01296.x

17. Gamal WM, Osman MM, Hammady A, Aldahshoury MZ, Hussein MM. Penile fracture: long-term results of surgical and conservative management. J Trauma. 2011;71:491-493. doi:10.1097/ TA.0b013e3182093113

18. Wong NC, Dason S, Bansal RK, Davies TO, Braga LH. Can it wait? A systematic review of immediate vs. delayed surgical repair of penile fractures. Can Urol Assoc J. 2017;11:53-60. doi:10.5489/ cuaj. 4032

19. Amer T, Wilson R, Chlosta P, et al. Penile fracture: a meta-analysis. Urol Int. 2016;96:315-329. doi:10.1159/000444884

20. Uygur MC, Gülerkaya B, Altuğ U, Germiyanoglu C, Erol D. 13 years' experience of penile fracture. Scand J Urol Nephrol. 1997;31:265-266.

21. Mobley EM, Fuchs ME, Myers JB, Brant WO. Update on plication procedures for Peyronie's disease and other penile deformities. Ther Adv Urol. 2012;4:335-346. doi:10.1177/1756287212448224

22. Langston JP, Carson CC. Peyronie disease: plication or grafting. Urol Clin North Am. 2011;38:207-216. doi:10.1016/j.ucl.2011.03.001

23. Gholami SS, Lue TF. Correction of penile curvature using the 16-dot plication technique: a review of 132 patients. $J$ Urol. 2002;167:2066-2069.

24. Perovic SV, Djinovic RP. Current surgical management of severe peyronie‘s disease. Arch Esp Urol. 2010;63:755-770.

25. Basiri A, Sarhangnejad R, Ghahestani SM, Radfar MH. Comparing absorbable and nonabsorbable sutures in corporeal plication for treatment of congenital penile curvature. Urol J. 2011;8:302-306.

\section{Publish your work in this journal}

Research and Reports in Urology is an international, peer-reviewed, open access journal publishing original research, reports, editorials, reviews and commentaries on all aspects of adult and pediatric urology in the clinic and laboratory including the following topics: Pathology, pathophysiology of urological disease; Investigation and treatment of urological disease; Pharmacology of drugs used for the treatment of urological disease. The manuscript management system is completely online and includes a very quick and fair peer-review system, which is all easy to use. Visit http://www.dovepress.com testimonials.php to read real quotes from published authors. 